\title{
Secondary haematological malignancies after radioimmunotherapy
}

\author{
Federica Gigli • Angelo Gardellini • Paola Bertazzoni • \\ Giovanni Martinelli
}

Received: 28 June 2011 / Accepted: 25 September 2011 / Published online: 11 October 2011

(C) Springer-Verlag 2011

\section{Dear Editor,}

Concerning the letter to the editor by Piccin et al. [1], we would like to report the experience of the Haematoncology Division of European Institute of Oncology. We recently observed two patients treated with radioimmunotherapy (RIT; 90Y-DOTATOC/Lu177-DOTATOC) because of the presence of neuroendrocrine tumours.

The first patient was a male of 75 years old; he had a bowel neuroendocrine tumour with secondary liver localizations. He developed an AML with trilineage dysplasia at 2 years following RIT, with this karyotype: $59, \mathrm{XYY},+4,+6$, $+10,+11,+11,+15,+16,-9,+20,+5 \operatorname{mar}[3] / 46, \mathrm{XY}[47]$. The blood count at diagnosis was WBC 2,270/mmc, platelets $44,000 / \mathrm{mmc}$ and $\mathrm{Hb} 8.6 \mathrm{~g} / \mathrm{dl}$.

The second patient was a male, 41 years old. He had a prostatic neuroendocrine tumour with secondary lymph nodes, bone and lung localizations. He developed a secondary AML at 4 years following RIT, with this karyotype: 43 50,XY,+1[8],del(1)(q21)[6],del(5)(q22q33) $[14],+\operatorname{del}(5)(\mathrm{q} 22 \mathrm{q} 33)[9],-7[13],+8[12],+9[13],+11[12], \mathrm{del}$ (12)(p12)[9],-14[14],-16[2],-17[12],-18[6],-18[3],+21[7], $+22[12][\mathrm{cp} 15] / 46, \mathrm{XY}[5]$. The blood count at diagnosis was WBC $18,560 / \mathrm{mmc}$, blasts $76 \%$, platelets $141,000 / \mathrm{mmc}, \mathrm{Hb}$ $8.5 \mathrm{~g} / \mathrm{dl}$.

The first patient received from 2005 to 2006 a cumulative dose of Y90 DOTATOC $200 \mathrm{mCi}$, then received LU 177 DOTATOC from 2006 to 2009 (with a cumulative dose of more than $300 \mathrm{mCi})$. The second patient received Y90 DOTATOC from 2006 to 2007 with a cumulative dose of $200 \mathrm{mCi}$.

Both patients receiving standard induction chemotherapy for acute leukaemia (ARA-C and daunorubicin) did not achieve any remission for leukaemia showing a resistant/ refractory disease; the first patient died after 113 days following diagnosis, the second one was lost to follow-up after 58 days following diagnosis. It is well known as RIT could induce renal toxicity but is not well established the possible incidence of secondary tumours, as well as haematological malignancies, as late complications of this treatment.

The presence of these complications in our patients as well as the other one presented by Piccin et al. [1] raises the issue of how to investigate the real incidence of such late complications. We suggest data collection from all patients with neuroendocrine tumours treated with RIT in a specific registry to evaluate the real incidence of haematological malignancies and solid tumours that may affect clinical results achieved in such indolent disease, using radio-labelled compounds.

\section{Reference}

1. Piccin A, Grana CM, Negri G, Pusceddu I, Paganelli G, Cortelazzo S (2011) Secondary acute myeloid leukemia after peptide receptor radionuclide therapy. Ann Hematol. doi:10.1007/s00277-011-1237-9

F. Gigli $(\bowtie) \cdot$ A. Gardellini $•$ P. Bertazzoni $•$ G. Martinelli European Institute of Oncology_Division of Hematoncology, Milan, Italy

e-mail: federica.gigli@ieo.it

F. Gigli · A. Gardellini · P. Bertazzoni $\cdot$ G. Martinelli

Via Ripamonti 435,

20141 Milan, Italy 